\title{
MR Imaging Grading System for Skull Base Chordoma
}

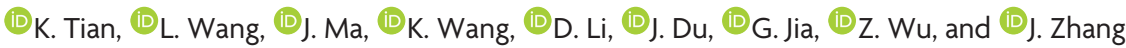

\begin{abstract}
BACKGROUND AND PURPOSE: Skull base chordoma has been widely studied in recent years, however, imaging characteristics of this tumor have not been well elaborated. The purpose of this study was to establish an MR imaging grading system for skull base chordoma.

MATERIALS AND METHODS: In this study, 156 patients with skull base chordomas were retrospectively assessed. Tumor-to-pons signal intensity ratios were calculated from pretreatment MR images $R_{T 1}$ (ratio of tumor to pons signal intensity in T1 FLAIR sequence), $R_{T 2}$ (ratio of tumor to pons signal intensity in $T 2$ sequence) and $R_{E N}$ (ratio of tumor to pons signal intensity in enhanced T1 FLAIR sequence), and significant ratios for overall survival and progression-free survival were selected to establish a grading system. Clinical variables among different MR imaging grades were then analyzed to evaluate the usefulness of the grading system.
\end{abstract}

RESULTS: $\mathrm{R}_{\mathrm{T} 2}(P<.001)$ and $\mathrm{R}_{\mathrm{EN}}(P=.04)$ were identified as significant variables affecting progression-free survival. After analysis, the classification criteria were set as follows: MR grade I, $R_{T 2}>2.49$ and $R_{E N} \leq 0.77$; $M R$ grade II, $R_{T 2}>2.49$ and $R_{E N}>0.77$, or $R_{T 2} \leq 2.49$ and $\mathrm{R}_{\mathrm{EN}} \leq 0.77$; and $\mathrm{MR}$ grade III, $\mathrm{R}_{\mathrm{T} 2} \leq 2.49$ and $\mathrm{R}_{\mathrm{EN}}>0.77$. MR grade III tumors had a more abundant tumor blood supply than $M R$ grade I tumors $(P<.001)$, and the intraoperative blood loss of MR grade III tumors was higher than that of MR grade I tumors $(P=.002)$. Additionally, skull base chordoma progression risk increased by 2.071 times for every single MR grade increase $(P<.001)$.

CONCLUSIONS: A higher $\mathrm{R}_{\mathrm{T} 2}$ value was a negative indicator of tumor progression, whereas a higher $\mathrm{R}_{\mathrm{EN}}$ value was a positive risk factor of tumor progression. MR grade III tumors showed a more abundant blood supply than MR grade I tumors, and the risk of skull base chordoma progression increased with every single MR grade increase.

ABBREVIATIONS: OS = overall survival; $\mathrm{PFS}=$ progression-free survival; $\mathrm{SBC}=$ skull base chordoma; $\mathrm{SI}$ = signal intensity

C hordoma is a malignant tumor that originates from notochord remnants, and this tumor often exhibits mild-to-moderate enhancement. It comprises $1.8 \%-4.3 \%$ of bone tumors and

Received October 14, 2016; accepted after revision January 22, 2017.

From the Department of Neurosurgery (K.T., L.W., J.M., K.W., D.L., G.J., Z.W., J.Z.), Beijing Tiantan Hospital, Capital Medical University, Beijing, China; China National Clinical Research Center for Neurological Diseases (K.T., L.W., J.M., K.W., D.L., G.J., Z.W., J.Z.), Beijing, China; Center of Brain Tumor (K.T., L.W., J.M., K.W., D.L., G.J., Z.W., J.Z.), Beijing Institute for Brain Disorders, Beijing, China; Beijing Key Laboratory of Brian Tumor (K.T., L.W., J.M., K.W., D.L., G.J., Z.W., J.Z.), Beijing, China; Department of Neuropathology (J.D), Beijing Neurosurgical Institute, Capital Medical University, Beijing, China; China National Clinical Research Center for Neurological Diseases (J.D.), Center of Brain Tumor, Beijing, China; and Institute for Brain Disorders (J.D.), Beijing Key Laboratory of Brain Tumor, Beijing, China.

This work was supported in part by the National Natural Science Foundation of China (grant no. 81472370 and 81541146), the Natural Science Foundation of Beijing Municipality, China (grant No. 7142052 and 7163212), and the National High Technology Research and Development Program 863 (grant no. 2014AA020610).

Please address correspondence to Junting Zhang, MD, and Liang Wang, MD, Department of Neurosurgery, Beijing Tiantan Hospital, Capital Medical University, Tiantan Xili 6, Dongcheng District, Beijing, 100050, China; e-mail: zhangjunting2003@aliyun.com and saintage7@126.com

- Indicates open access to non-subscribers at www.ajnr.org

http://dx.doi.org/10.3174/ajnr.A5152
$3.9 \%-6.1 \%$ of malignant bone tumors, ${ }^{1-3}$ and it shows a marked predilection for the axial skeleton. Chordoma primarily occurs in the skull base (32\%-42\%) and sacrococcygeal region $(29.2 \%) .{ }^{4,5}$ The prevalence of chordomas is $0.08-0.089$ per 100,000 , and males $(0.01-0.016$ per 100,000$)$ have a higher incidence than females $(0.06-0.066$ per 100,000$) .^{4-6}$ Chordoma is locally aggressive and may destroy surrounding bone. Skull base chordoma (SBC) often involves vital blood vessels, cranial nerves, and other important structures. Extensive resection of a skull base chordoma is difficult and may result in severe complications. ${ }^{7}$ Chemotherapy usually has a minimal effect on chordomas, and the current best treatment is radical resection plus postoperative radiation therapy. ${ }^{8,9}$ The median survival for patients with SBC is 151 months. ${ }^{10}$ In recent years, new technologies such as endoscopy, intraoperative navigation, and electrophysiologic monitoring have facilitated more radical resections. ${ }^{11}$ Although the proton beam, carbon ion, modulated and stereotactic techniques were applied in radiation therapy, the progression and mortality rates of skull base chordoma are still very high. ${ }^{11-14}$

The diagnosis and classification of chordoma primarily de- 
pend on histopathologic evaluation and preoperative imaging data. Chordoma has 3 histologic types: conventional, chondroid, and dedifferentiated. ${ }^{15}$ Conventional chordoma is the most common type, and patients with chondroid chordoma are reported to have the best prognoses. ${ }^{8}$ Chordoma often shows low density and bone destruction on $\mathrm{CT} .{ }^{16} \mathrm{MR}$ imaging is superior in detecting the tumor and delineating its extent. ${ }^{17}$ Chordomas have a highly heterogeneous appearance on MR imaging, demonstrating hypo-
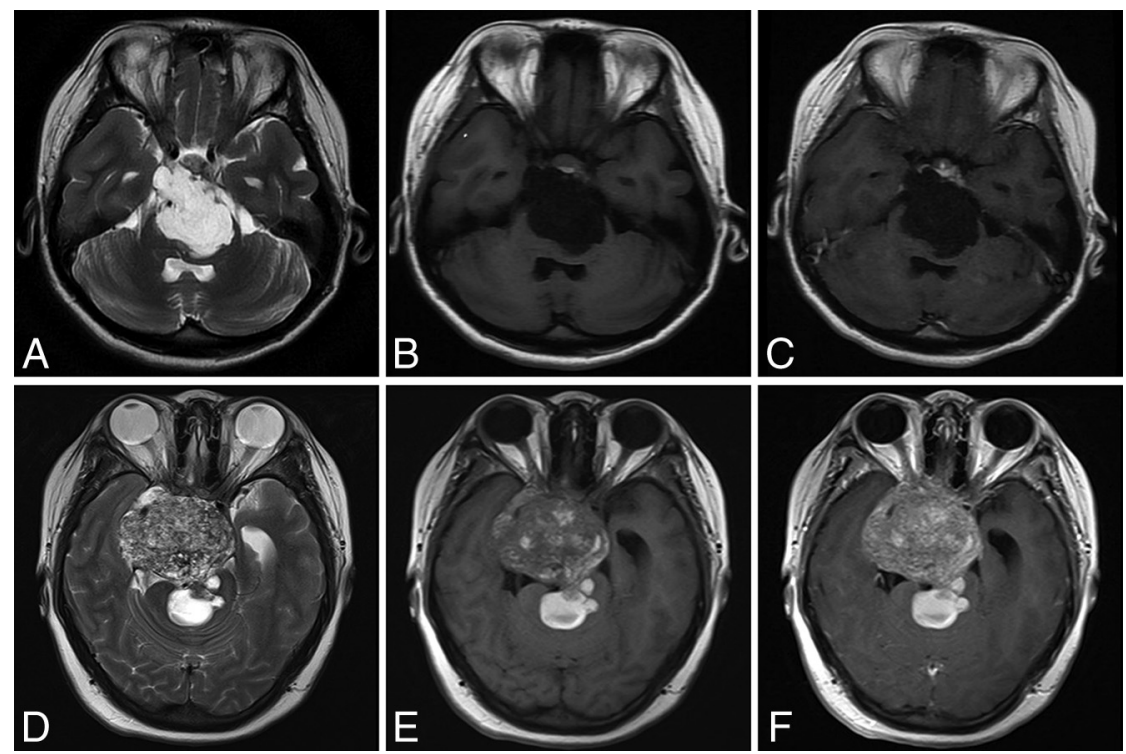

FIG 1. MR imaging of 2 patients with SBC. Patient $1(A-C)$, 21-years of age. Pathologic findings were conventional chordoma. The patient underwent subtotal tumor resection with no progression at 48 months. A, Axial T2-weighted MR imaging. Tumor demonstrates homogeneous high signal intensity. $B$, Axial T1 FLAIR-weighted MR imaging. Tumor has relatively homogeneous hypointense signal compared with the pons. $C$, Enhanced T1 FLAIR MR imaging shows no enhancement of the lesion. Patient $2(D-F), 25$ years of age. Pathologic findings revealed conventional chordoma with necrosis and nuclear division. This patient underwent subtotal tumor resection with tumor progression at 8 months. D, Axial T2-weighted MR imaging demonstrates tumor heterogeneity. The signal intensity is relatively lower than that in patient 1. E, Axial T1 FLAIR MR imaging. The tumor is heterogeneous and hyperintense compared with the pons. $F$, Enhanced TI FLAIR MR imaging. Tumor exhibits moderate enhancement. to isointensity on T1 sequences and moderate-to-very-high intensity on $\mathrm{T} 2$ sequences. The tumor may exhibit minimal-tooderate enhancement on enhanced T1 sequences (Fig 1). The ical significance of this MR imaging heterogeneity has not

We thought that the clinical features and prognosis of SBCs were associated with the characteristics on MR imaging (Figs 1 and 2). The purpose of this study was to explore the value of MR signal intensity (SI) in establishing a grading system for SBC.

\section{MATERIALS AND METHODS Overview}

This study was approved by the ethics committee of Beijing Tiantan Hospital, Capital Medical University, and informed consent was acquired from all patients. There were no financial conflicts of interest associated with this project. The method used in this study was similar to that in the study of Tian et al. ${ }^{14}$ All MR imaging data used in this study were acquired before any treatment, and all the enrolled patients underwent an operation in our hospital.

\section{Patients}

In this study, 242 patients underwent an operation for SBC from February 2005 to December 2014 in the skull base ward of our hospital. We developed inclusion and exclusion criteria as follows: The inclusion criteria were the following: 1) All patients had their primary operation at our institute, 2) no prior treatment (eg, biopsy, radiation therapy, and chemother-
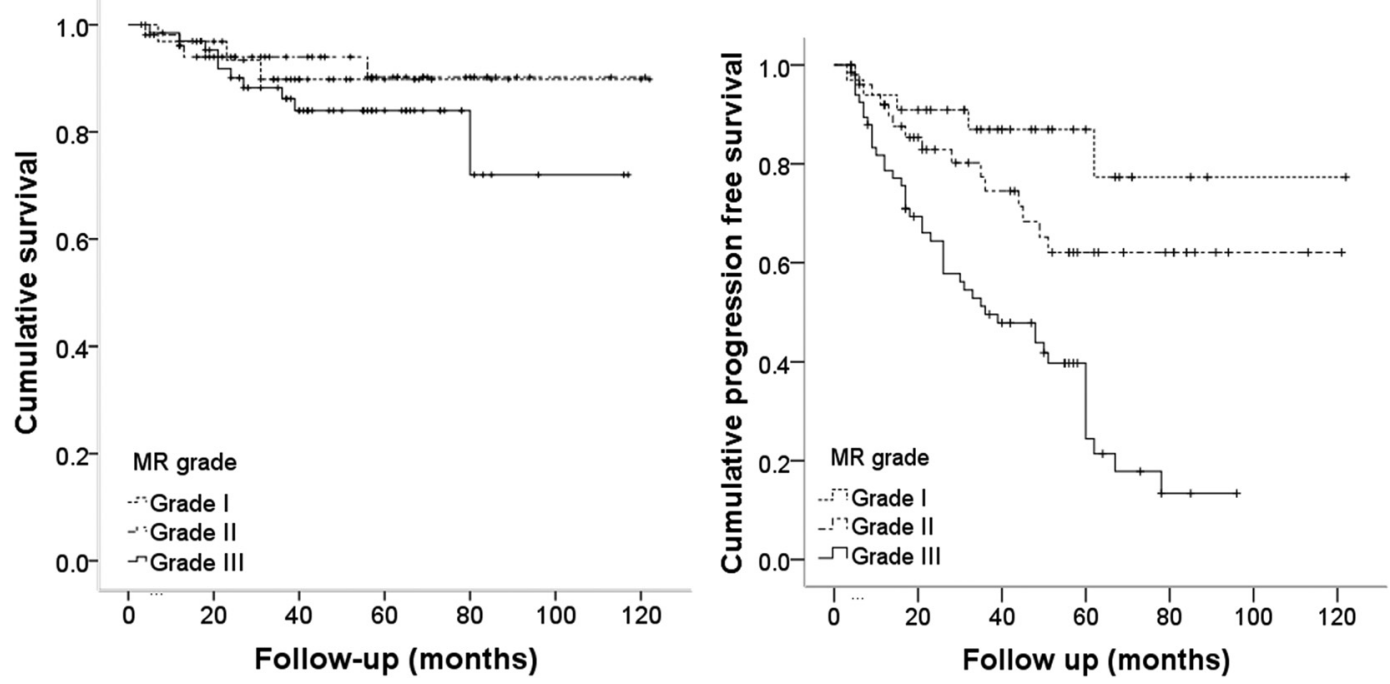

FIG 2. Kaplan-Meier analysis illustrating survival (left) and progression-free survival (right) for different MR imaging grades. There were no differences in overall survival among the 3 MR grade groups (log-rank $=1.669, P=.43$ ). Progression-free survival was different among the 3 MR grades (log-rank $=25.889, P<.001)$, with grade III tumors being associated with shorter progression-free survival than grade I (log-rank $=18.561$, $P<.001)$ and grade II (log-rank $=12.668, P<.001)$ tumors. 
apy) had been attempted, and 3) there was availability of MR images before the operation (including T1 FLAIR, T2, and enhanced T1 FLAIR sequences). The exclusion criteria were lack of a complete MR imaging examination before treatment and the presence of other significant diseases that might affect survival.

\section{Clinical Analysis}

Demographic information for patients was obtained from medical records. The data included surgical approaches, tumor blood supply, tumor consistency, intraoperative blood loss, and postoperative radiation therapy. The tumor blood supply was classified as either abundant or poor. Tumor consistency was recorded as either soft or hard (the latter included heterogeneous tumors with both soft and hard components). We followed patients in clinics or by telephone. Patients who were lost to follow-up were not included in the subsequent regression analyses. Tumor progression stands for tumor growth after operation.

\section{Histopathologic Analysis}

All histologic specimens were examined by 2 experienced pathologists with $>10$ years' experience in chordoma analysis. According to the International Agency for Research on Cancer, the lesions include conventional, chondroid, and dedifferentiated types. ${ }^{15}$ No dedifferentiated chordomas were found; thus, the group included only conventional and chondroid chordomas.

\section{MR Imaging Protocol}

MR imaging examinations were performed by using a 3T Magnetom Tim Trio scanner (Siemens, Erlangen, Germany). T1 FLAIR, T2, and enhanced T1 FLAIR sequences were included in each patient's images. The TR/TE range was 1850-2500/9.4-19.8 ms for the T1 FLAIR sequence and 4500-6000/84-97 ms for the T2 sequence. Gadopentetate dimeglumine was injected at a concentration of $0.2 \mathrm{~mL} / \mathrm{kg}(0.5 \mathrm{~mol} / \mathrm{L})$. Scanning was performed $2 \mathrm{~min}$ utes after the injection. The TR/TE ranges for the enhanced T1 FLAIR sequence were 1850-2500/9.4-19.8 ms. All MR imaging data were analyzed in the PACS.

\section{MR Imaging Analysis}

All MR imaging data were evaluated by 2 radiologists. MR image quality was evaluated first. For diagnosis, all tumor images were free of significant artifacts. The maximum diameters of the tumors in 3 perpendicular dimensions were measured, and the largest value was recorded as the "largest diameter." Categories were defined as follows: morphology, with and without lobulation; location, occipitocervical and other types; and resection degree, aggressive (>90\%) and nonaggressive ( $\leq 90 \%)$ resection.

Finally, tumor SI was measured in the PACS. Because image noise and other conditions might affect the SI in MR images, normalization was performed by selecting an area as a control. The pons was selected as our control. The SI of a small region in the pons was measured in each patient, and SI values of T1 FLAIR, T2, and enhanced T1 FLAIR sequences were obtained separately. The average tumor SI ( $\mathrm{S}_{\mathrm{TT} 1 \text { FLAIR }}, \mathrm{S}_{\mathrm{TT} 2}$, and $\left.\mathrm{SI}_{\text {tumor enhance }}\left[\mathrm{S}_{\mathrm{TEN}}\right]\right)$ and the pons SI ( $\mathrm{S}_{\mathrm{PT} 1}$ FLAIR, $\mathrm{S}_{\mathrm{PT} 2}$, $\left.\mathrm{SI}_{\text {pons enhance }}\left[\mathrm{S}_{\mathrm{PEN}}\right]\right)$ was calculated. Average SI ratios of tumor to pons $\left(\mathrm{R}_{\mathrm{T} 1 \text { FLAIR }}, \mathrm{R}_{\mathrm{T} 2}\right.$, Ratio enhance $\left.\left[\mathrm{R}_{\mathrm{EN}}\right]\right)$ were then calculated,
Table 1: Continuous variables for patients with SBC ${ }^{\mathrm{a}}$

\begin{tabular}{lccccc}
\hline & Minimum & Maximum & Mean & Median & \multicolumn{1}{c}{ SD } \\
\hline Age $(\mathrm{yr})$ & 5 & 67 & 36.38 & 38 & 14.64 \\
Largest diameter $(\mathrm{mm})$ & 15 & 86 & 42.04 & 42 & 12.75 \\
Blood loss $(\mathrm{mL})$ & 100 & 5500 & 897.12 & 700 & 730.27 \\
$\mathrm{R}_{\mathrm{T1}} \mathrm{b}$ & 0.11 & 1.99 & 0.57 & 0.54 & 0.23 \\
$\mathrm{R}_{\mathrm{T} 2} \mathrm{~b}$ & 1.10 & 4.10 & 2.44 & 2.40 & 0.54 \\
$\mathrm{R}_{\mathrm{EN}} \mathrm{b}$ & 0.21 & 2.24 & 1.01 & 1.01 & 0.40 \\
\hline
\end{tabular}

a Values of minimum and maximum are raw data.

${ }^{b} R_{T}, R_{T 2}$, and $R_{E N}$ were calculated according to the formula in the text.

and $\mathrm{R}_{\mathrm{T} 1 \text { FLAIR }}$, $\mathrm{R}_{\mathrm{T} 2}$ and $\mathrm{R}_{\mathrm{EN}}$ were used as the $\mathrm{SI}$ ratios of the tumor to the pons in the T1 FLAIR, T2, and enhanced T1 FLAIR sequences, respectively. We used the following formulas:

$$
\begin{aligned}
& \mathrm{R}_{\mathrm{T} 1 \text { FLAIR }}=\mathrm{S}_{\mathrm{TT} 1 \text { FLAIR }} / \mathrm{S}_{\mathrm{PT} 1 \text { FLAIR }} \\
& \mathrm{R}_{\mathrm{T} 2}=\mathrm{S}_{\mathrm{TT} 2} / \mathrm{S}_{\mathrm{PT} 2} \\
& \mathrm{R}_{\mathrm{EN}}=\mathrm{S}_{\mathrm{TEN}} / \mathrm{S}_{\mathrm{PEN}} .
\end{aligned}
$$

\section{Statistical Analysis}

Statistical analyses were performed by using SPSS software (SPSS Statistics 20.0; IBM, Armonk, New York). The effects of $\mathrm{R}_{\text {T1 FLAIR, }}$ $\mathrm{R}_{\mathrm{T} 2}$, and $\mathrm{R}_{\mathrm{EN}}$ on overall survival (OS) and progression-free survival (PFS) were analyzed with the Cox model. Significant variables were then selected to establish the SBC MR imaging grading system. Receiver operating characteristic analysis was used to set cutoff values.

Rank sum and $t$ tests were used in the analysis of the distributions of continuous variables among different MR imaging subgroups. A $\chi^{2}$ test was used in analyzing the distributions of categoric variables among different MR imaging subtypes. The Kaplan-Meier test was used in assessing OS and PFS among different MR imaging groups. In the OS and PFS analysis, all factors were first included in univariate analysis separately; then, multivariate analysis was conducted with the inclusion criterion of 0.1 . A $P$ value $<.05$ indicated statistical significance.

\section{RESULTS}

Of the 242 patients with SBC, 183 individuals underwent a primary operation. For 21 of these patients, pretreatment MR images were not available. For the remaining 162 patients, enhanced T1 FLAIR sequences were not available for 3 patients, and the MR images of another 3 patients were unobtainable for review. Therefore, 156 patients were included in the final analysis.

There were 63 females and 93 males (1:1.5), and the patients' ages ranged from 5 to 67 years (median, $38 \pm 14.6$ years). No significant differences in age were found between sexes $(P=.18)$. The median follow-up time was 42 months (range, 3-122 months); 3 patients were lost to follow-up, and 17 patients died (mortality rate of $11.1 \%$ ). One died of a brain stem ischemic infarction, 2 died of tumor apoplexy, and the remaining 14 died from complications caused by tumor recurrence. Sixty-five (42.5\%) patients experienced tumor progression. Other variables are listed in Tables 1 and 2.

Univariate Cox regression analysis indicated that decreased $\mathrm{R}_{\mathrm{T} 2}$ (hazard ratio $=0.332 ; 95 \% \mathrm{CI}, 0.201-0.548 ; P<.001$ ) and increased $\mathrm{R}_{\mathrm{EN}}$ (hazard ratio $=1.836 ; 95 \% \mathrm{CI}, 1.032-3.264 ; P=$ $.04)$ were significant adverse variables for PFS. Therefore, $\mathrm{R}_{\mathrm{T} 2}$ and $\mathrm{R}_{\mathrm{EN}}$ values were included in the MR imaging classification. According to receiver operating characteristic analysis, the cutoff value for 
Table 2: Categoric variables for patients with $\mathrm{SBC}^{\mathrm{a}}$

\begin{tabular}{|c|c|c|c|c|c|c|}
\hline & \multirow{2}{*}{$\begin{array}{l}\text { No. of } \\
\text { Patients }\end{array}$} & \multirow{2}{*}{$\begin{array}{l}\text { Lost to } \\
\text { Follow-Up }\end{array}$} & \multicolumn{2}{|c|}{ Survival } & \multicolumn{2}{|c|}{ Progression } \\
\hline & & & Survival & Death & $\mathbf{Y}$ & $\mathbf{N}$ \\
\hline \multicolumn{7}{|l|}{ Sex } \\
\hline Female & 62 & 1 & 56 & 6 & 25 & 37 \\
\hline Male & 91 & 2 & 80 & 11 & 40 & 51 \\
\hline \multicolumn{7}{|l|}{ Location } \\
\hline OC & 26 & 0 & 23 & 3 & 15 & 11 \\
\hline Other & 127 & 3 & 113 & 14 & 50 & 77 \\
\hline \multicolumn{7}{|l|}{ Lobulation } \\
\hline Y & 79 & 1 & 70 & 9 & 38 & 41 \\
\hline $\mathrm{N}$ & 74 & 2 & 66 & 8 & 27 & 47 \\
\hline \multicolumn{7}{|l|}{ Approach } \\
\hline Cranial & 129 & 3 & 114 & 15 & 51 & 78 \\
\hline Nasal & 24 & 0 & 22 & 2 & 14 & 10 \\
\hline \multicolumn{7}{|l|}{ Blood supply } \\
\hline Abundant & 83 & 2 & 72 & 11 & 45 & 38 \\
\hline Poor & 70 & 1 & 64 & 6 & 20 & 50 \\
\hline \multicolumn{7}{|l|}{ Texture } \\
\hline Soft & 73 & 2 & 62 & 11 & 25 & 48 \\
\hline Hard & 80 & 1 & 74 & 6 & 40 & 40 \\
\hline \multicolumn{7}{|l|}{ Resection grade } \\
\hline$>90 \%$ & 115 & 3 & 103 & 12 & 45 & 70 \\
\hline$\leq 90 \%$ & 38 & 0 & 33 & 5 & 20 & 18 \\
\hline \multicolumn{7}{|l|}{ Histopathology } \\
\hline Conventional & 94 & 1 & 80 & 14 & 46 & 48 \\
\hline Chondroid & 59 & 2 & 56 & 3 & 19 & 40 \\
\hline \multicolumn{7}{|l|}{ Postradiotherapy } \\
\hline $\mathrm{Y}$ & 15 & 0 & 13 & 2 & 5 & 10 \\
\hline $\mathrm{N}$ & 138 & 3 & 123 & 15 & 60 & 78 \\
\hline Total & 153 & 3 & 136 & 17 & 65 & 88 \\
\hline
\end{tabular}

Note:-OC indicates occipitocervical; $Y$, yes; $N$, no.

a Number of patients is raw data.

$\mathrm{R}_{\mathrm{T} 2}$ was 2.49, and it was 0.77 for $\mathrm{R}_{\mathrm{EN}}$. The following classification grades were established: $\mathrm{MR}$ grade $\mathrm{I}, \mathrm{R}_{\mathrm{T} 2}>2.49$ and $\mathrm{R}_{\mathrm{EN}} \leq 0.77 ; \mathrm{MR}$ grade II, $\mathrm{R}_{\mathrm{T} 2}>2.49$ and $\mathrm{R}_{\mathrm{EN}}>0.77$, or $\mathrm{R}_{\mathrm{T} 2} \leq 2.49$ and $\mathrm{R}_{\mathrm{EN}} \leq 0.77$; and MR grade III, $\mathrm{R}_{\mathrm{T} 2} \leq 2.49$ and $\mathrm{R}_{\mathrm{EN}}>0.77$.

Analysis of the distributions of SBC characteristics among the different MR grades showed that MR grade III tumors had more abundant blood supply than MR grade I tumors $(P<.001)$, as well as greater intraoperative blood loss $(800$ versus $500 \mathrm{~mL}, P=$ .002). The distribution of SBC pathologic types among the different MR grades was not significantly different $(P=.56)$ (Table 3$)$.

Kaplan-Meier analysis of OS showed no significant differences among the different MR grades (Fig 2, left). However, in KaplanMeier analysis of tumor progression, MR grade III tumors were associated with shorter PFS than MR grade I $(P<.001)$ and MR grade II tumors $(P<.001)$ (Fig 2 , right). Univariate analysis revealed that tumor blood supply, resection grade, tumor consistency, histopathology, tumor location, surgical approaches, and MR grades were potentially significant risk factors for tumor progression $(P<$ .001). After including the above variables in multivariate analysis, tumor blood supply, resection grade, tumor consistency, histopathology, and MR grade were independent variables for PFS and the risk of SBC progression increased by 2.071 times for every single MR grade increase (95\% CI: $1.376-3.118, P<.001)$ (Fig 3).

\section{DISCUSSION}

In this retrospective study, the MR SI of patients with SBC was incorporated into statistical analyses, and SBCs were classified into $3 \mathrm{MR}$ grades according to $\mathrm{R}_{\mathrm{T} 2}$ and $\mathrm{R}_{\mathrm{EN}}$ values. It was found
Table 3: The distributions of variables of patients with SBC in different MR imaging grades

\begin{tabular}{|c|c|c|c|c|}
\hline & Grade I & Grade II & Grade III & $P$ Value \\
\hline Age (yr) & $28^{a}$ & $39^{a}$ & $40^{a}$ & $.06^{\mathrm{b}}$ \\
\hline Largest diameter (mm) & $45^{\mathrm{a}}$ & $37^{\mathrm{a}}$ & $43^{a}$ & $.08^{b}$ \\
\hline Blood loss (mL) & $500^{a}$ & $800^{a}$ & $800^{a}$ & $.002^{\mathrm{c}, \mathrm{d}}$ \\
\hline Sex & & & & $.45^{\mathrm{e}}$ \\
\hline Female & 14 & 25 & 24 & \\
\hline Male & 19 & 29 & 45 & \\
\hline Location & & & & $.79^{\mathrm{e}}$ \\
\hline OC & 7 & 8 & 11 & \\
\hline Other & 26 & 46 & 58 & \\
\hline Lobulation & & & & $.42^{\mathrm{e}}$ \\
\hline$Y$ & 17 & 24 & 39 & \\
\hline$N$ & 16 & 30 & 30 & \\
\hline Blood supply & & & & $.000^{\mathrm{d}, \mathrm{e}}$ \\
\hline Abundant & 9 & 28 & 48 & \\
\hline Poor & 24 & 26 & 21 & \\
\hline Texture & & & & $.05^{\mathrm{e}}$ \\
\hline Soft & 22 & 24 & 29 & \\
\hline Hard & 11 & 30 & 40 & \\
\hline Resection grade & & & & $.43^{\mathrm{e}}$ \\
\hline$>90 \%$ & 25 & 44 & 49 & \\
\hline$\leq 90 \%$ & 8 & 10 & 20 & \\
\hline Histopathology & & & & $.56^{\mathrm{e}}$ \\
\hline Conventional & 22 & 30 & 43 & \\
\hline Chondroid & 11 & 24 & 26 & \\
\hline Postradiotherapy & & & & $.39^{e}$ \\
\hline$Y$ & 4 & 7 & 4 & \\
\hline $\mathrm{N}$ & 29 & 47 & 65 & \\
\hline
\end{tabular}

Note:-OC indicates occipitocervical; $Y$, yes; N, no.

${ }^{a}$ Median value.

b Variance analysis (Student-Newman-Keuls).

${ }^{c}$ Wilcoxon rank sum test.

${ }^{d} p<.05$

${ }^{\mathrm{e}} \chi^{2}$ test.

that MR grade III tumors had more abundant blood supply than MR grade I tumors. Furthermore, the risk of SBC progression increased by 2.071 times for every single MR grade increase in the MR classification system.

MR imaging is useful not only for diagnosing disease but also in predicting prognosis and tumor classification. The MR SI and SI ratio of a lesion have been considered important indicators in many studies. ${ }^{18-21}$ However, chordomas show substantial heterogeneity on MR images, and MR imaging has previously been used only to aid in the diagnosis of SBC. No previous studies have reported the relationships between $\mathrm{MR}$ imaging features and SBC outcomes.

In the present study, tumor and pons signal intensities were measured in the PACS with a straightforward measurement process that ensures the acquisition of accurate data. ${ }^{22}$ We calculated $\mathrm{R}_{\mathrm{T} 1 \text { FLAIR }}, \mathrm{R}_{\mathrm{T} 2}$, and $\mathrm{R}_{\mathrm{EN}}$ values to represent the tumor $\mathrm{SI}$ in each sequence while eliminating confounding factors caused by MR imaging conditions among different patients. Although there was no evidence that the MR signal ratio is a risk factor for mortality in statistical analysis, our results showed that a higher $\mathrm{R}_{\mathrm{T} 2}$ value predicted diminished tumor progression and that a higher $\mathrm{R}_{\mathrm{EN}}$ value predicted more rapid tumor progression. We therefore established MR grades on the basis of these values. Multivariate analysis of tumor progression indicated that MR grade was a significant risk factor and that the risk of SBC progression increased as the MR grade increased. 


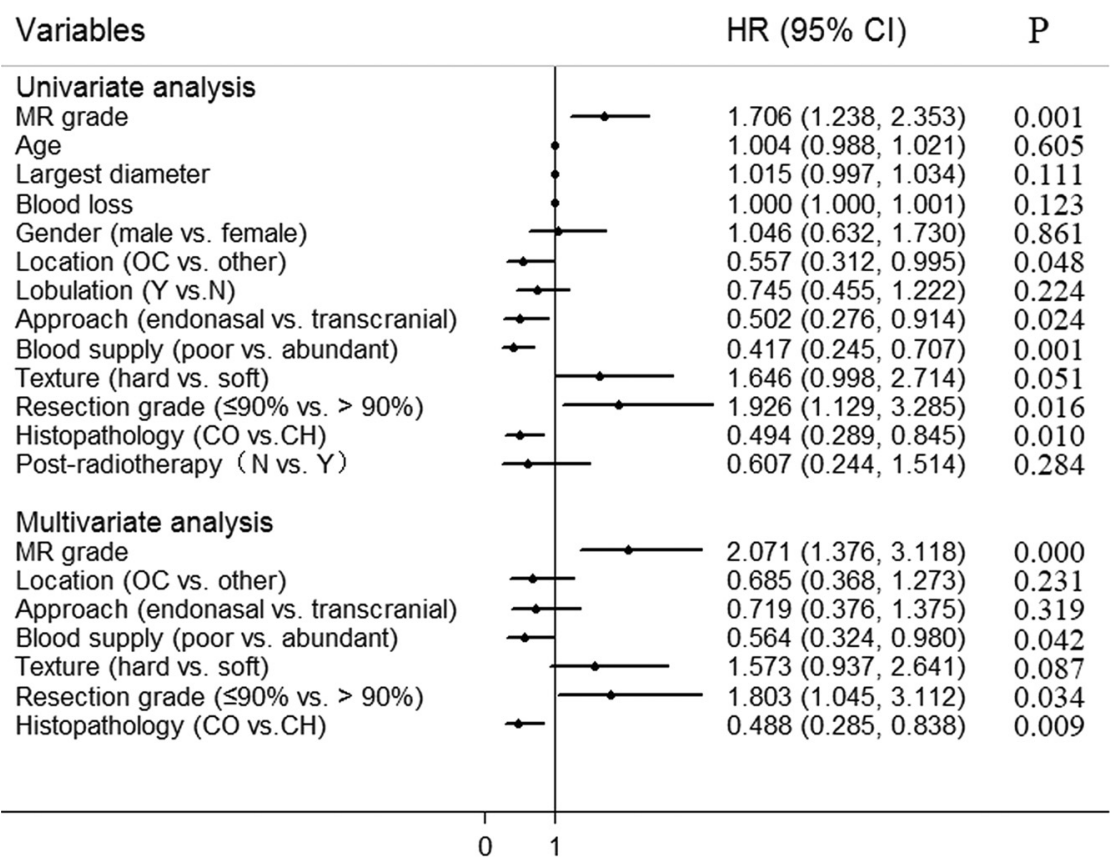

FIG 3. Univariate and multivariate Cox regression models for tumor progression risk. The black dots indicate odds ratio, and the horizontal line represents $95 \%$ confidence intervals. N indicates no; $\mathrm{Y}$, yes; OC, occipitocervical; $\mathrm{CO}$, conventional; $\mathrm{CH}$, chondroid; $\mathrm{HR}$, hazard ratio.

with those in prior studies. However, SBC pathologic type is not significantly associated with MR grade. Indeed, MR SI did not differ between chondroid and conventional SBCs, and no other studies have reported differences in MR imaging features between different SBC pathologic types. This finding may be because differences in histopathologic levels are not necessarily reflected in imaging modalities. These results need to be confirmed in additional studies.

We enrolled 156 patients with primary SBC in this study, and to the best of our knowledge, this represents the largest primary SBC single-center study. The singlecenter source avoided the heterogeneity occasionally encountered in multicenter studies. Additionally, we demonstrated the utility of MR SI ratios for SBC grading and confirmed the validity of our MR grading system. We also have demonstrated that the simple ratio of the tumor to the pons allows easy determination of SBC MR grade. This grading system can

Chordomas can be classified into conventional, chondroid, and dedifferentiated types based on histopathologic manifestations. Conventional chordoma is the most common type, and chondroid and dedifferentiated chordomas exhibit the most favorable and worst outcomes, respectively. ${ }^{9,23,24}$ Our results are consistent with those in previous reports. Although pathologic confirmation is the criterion standard for the diagnosis of SBC and pathologic type is an independent variable in the PFS analysis, the MR grading method for SBC was more useful for predicting the prognosis of patients with SBC. This usefulness derived from the following: First, there was a relatively uniform distribution of the $3 \mathrm{MR}$ grades of SBC; second, the MR grade can be immediately determined after an initial MR imaging examination, which is far earlier than a pathologic diagnosis; and third, the grading process is simple because the measurement of SI and the following calculation are both straightforward. This feature makes this technique more accessible to neurosurgeons and radiologists.

Prior studies have discussed the association between MR SI and lesion blood supply. ${ }^{25}$ They found that tumors with an abundant blood supply have lower $\mathrm{R}_{\mathrm{T} 2}$ values. We produced similar results in the present study, showing that MR grade III tumors (low $\mathrm{R}_{\mathrm{T} 2}$ and high $\mathrm{R}_{\mathrm{EN}}$ ) had a more abundant blood supply than MR grade I tumors (high $\mathrm{R}_{\mathrm{T} 2}$ and low $\mathrm{R}_{\mathrm{EN}}$ ) and that the former are associated with greater intraoperative blood loss than the latter. This finding is useful for preoperative evaluations of tumor blood supply and is of great significance for clinical practice. Prior knowledge of this factor may alter therapy, such as in preparing adequate quantities of blood, altering a planned operative approach, and in anticipating other measures for potentially significant hemorrhage.

In the present study, chondroid SBCs were associated with a longer PFS than conventional SBCs, and this finding is consistent be widely used. Additionally, the system was useful for predicting the progression of SBC in early tumor stages. Finally, these ratios can also be used to evaluate tumor blood supply, which is of therapeutic significance.

There were limitations to the current study. First, the relatively short follow-up was not sufficient for analyzing long-term outcomes; accordingly, the incidence of terminal events was relatively low for the OS and PFS. Second, the patients were grouped on the basis of retrospective assessments; therefore, further prospective studies are needed to validate the effectiveness of the grading system.

\section{CONCLUSIONS}

The tumor-to-pons SI ratio is of diagnostic and potential therapeutic significance for patients with SBC. A higher $\mathrm{R}_{\mathrm{T} 2}$ value predicted slow tumor progression, whereas a higher $\mathrm{R}_{\mathrm{EN}}$ value was a risk factor for tumor progression. A grading system based on $\mathrm{R}_{\mathrm{T} 2}$ and $\mathrm{R}_{\mathrm{EN}}$ was useful for predicting tumor blood supply and SBC progression. MR grade III tumors have a more abundant blood supply than MR grade I tumors, and the risk of SBC progression increases with each MR grade increase.

\section{REFERENCES}

1. Niu X, Xu H, Inwards CY, et al. Primary bone tumors: epidemiologic comparison of 9200 patients treated at Beijing Ji Shui Tan hospital, Beijing, China, with 10165 patients at Mayo Clinic, Rochester, Minnesota. Arch Pathol Lab Med 2015;139:1149-55 CrossRef Medline

2. Salisbury JR. The pathology of the human notochord. J Pathol 1993; 171:253-55 CrossRef Medline

3. Ho KL. Ecchordosis physaliphora and chordoma: a comparative ultrastructural study. Clin Neuropathol 1985;4:77-86 Medline

4. Chambers KJ, Lin DT, Meier J, et al. Incidence and survival patterns 
of cranial chordoma in the United States. Laryngoscope 2014;124: 1097-102 CrossRef Medline

5. McMaster ML, Goldstein AM, Bromley CM, et al. Chordoma: incidence and survival patterns in the United States, 1973-1995. Cancer Causes Control 2001;12:1-11 CrossRef Medline

6. Smoll NR, Gautschi OP, Radovanovic I, et al. Incidence and relative survival of chordomas: the standardized mortality ratio and the impact of chordomas on a population. Cancer 2013;119:2029-37 CrossRef Medline

7. Stüer C, Schramm J, Schaller C. Skull base chordomas: management and results. Neurol Med Chir (Tokyo) 2006;46:118-24; discussion 124-25 Medline

8. Jian BJ, Bloch OG, Yang I, et al. Adjuvant radiation therapy and chondroid chordoma subtype are associated with a lower tumor recurrence rate of cranial chordoma. J Neurooncol 2010;98:101-08 CrossRef Medline

9. Amendola BE, Amendola MA, Oliver E, et al. Chordoma: role of radiation therapy. Radiology 1986;158:839-43 CrossRef Medline

10. Jones PS, Aghi MK, Muzikansky A, et al. Outcomes and patterns of care in adult skull base chordomas from the Surveillance, Epidemiology, and End Results (SEER) database. J Clin Neurosci 2014;21: 1490-96 CrossRef Medline

11. Walcott BP, Nahed BV, Mohyeldin A, et al. Chordoma: current concepts, management, and future directions. Lancet Oncol 2012;13: e69-76 CrossRef Medline

12. Stacchiotti S, Sommer J. Building a global consensus approach to chordoma: a position paper from the medical and patient community. Lancet Oncol 2015;16:e71-83 CrossRef Medline

13. Wang L, Tian K, Wang K, et al. Factors for tumor progression in patients with skull base chordoma. Cancer Med 2016;5:2368-77 CrossRef Medline

14. Tian K, Wang L, Wang K, et al. Analysis of clinical features and outcomes of skull base chordoma in different age-groups. World Neurosurg 2016;92:407-17 CrossRef Medline

15. Flanagan AM, Yamaguchi T. World Health Organization (WHO) Classification of Tumors of Soft Tissue and Bone: Notochordal. Lyon: IARC Press; 2013:328-29
16. Meyer JE, Lepke RA, Lindfors KK, et al. Chordomas: their CT appearance in the cervical, thoracic and lumbar spine. Radiology 1984; 153:693-96 CrossRef Medline

17. Sze G, Uichanco LR 3rd, Brant-Zawadzki MN, et al. Chordomas: MR imaging. Radiology 1988;166:187-91 CrossRef Medline

18. Nowak J, Seidel C, Pietsch T, et al. Systematic comparison of MRI findings in pediatric ependymoblastoma with ependymoma and CNS primitive neuroectodermal tumor not otherwise specified. Neuro Oncol 2015;17:1157-65 CrossRef Medline

19. Takashima S, Sone S, Horii A, et al. Major salivary gland lesions: correlation of MR findings with flow cytometric DNA analysis and prognosis. AJR Am J Roentgenol 1996;167:1297-304 CrossRef Medline

20. Worthley SG, Reis ED, Helft G, et al. Serial magnetic resonance imaging correlates with neurological outcome in an experimental model of spinal cord ischemia. Spinal Cord 2008;46:222-27 CrossRef Medline

21. Massaro AN, Kadom N, Chang T, et al. Quantitative analysis of magnetic resonance images and neurological outcome in encephalopathic neonates treated with whole-body hypothermia. J Perinatol 2010;30:596-603 CrossRef Medline

22. El Kady RM, Choudhary AK, Tappouni R. Accuracy of apparent diffusion coefficient value measurement on PACS workstation: a comparative analysis. AJR Am J Roentgenol 2011;196:W280-84 CrossRef Medline

23. Makhdoomi R, Ramzan A, Khursheed N, et al. Clinicopathological characteristics of chordoma: an institutional experience and a review of the literature. Turk Neurosurg 2013;23:700-06 Medline

24. Wu Z, Zhang J, Zhang L, et al. Prognostic factors for long-term outcome of patients with surgical resection of skull base chordomas: 106 cases review in one institution. Neurosurg Rev 2010;33:451-56 CrossRef Medline

25. Shinmura R, Matsui O, Kobayashi S, et al. Cirrhotic nodules: association between MR imaging signal intensity and intranodular blood supply. Radiology 2005;237:512-19 CrossRef Medline 